\title{
I nfluence of adiposetissue derived mesenchymal stem cells in combination with injectable bone substitute on osteoclastogenesis in osteoporotic rats
}

\author{
Hanaa H. Ahmed ${ }^{* a}$, Wafaa Gh. Shousha ${ }^{b}$, El-Sayed M. El-Sayed Mahdy ${ }^{b}$, Laila A. Rashed ${ }^{\mathrm{c}}$, Sara M. Abdo ${ }^{\mathrm{b}}$ \\ ${ }^{a}$ Hormones Department, Medical Research Division, National Research Centre, Cairo, Egypt. \\ ${ }^{\mathrm{b}}$ Chemistry Department, Faculty of Science, Helwan University, Cairo, Egypt. \\ ${ }^{c}$ Medical Biochemistry Department, Faculty of Medicine,Cairo University, Cairo, Egypt.
}

\section{ARTICLE INFO}

\section{Article history:}

Received on: $23 / 06 / 2013$

Revised on: 19/07/2013

Accepted on: 05/08/2013

Available online: 30/08/2013

\section{Key words:}

Ovariectomized rats, osteoclastogenesis, adipose tissue derived mesenchymal stem cells, calcium phosphate composite.

\begin{abstract}
The present study was designed to evaluate the influence of adipose tissue derived mesenchymal stem cell (ASCs) with or without calcium phosphate composite on osteoclastogenesis in osteoporotic rats. Mesenchymal stem cells (MSCs) were harvested from adipose tissue of both the omentum and the inguinal fat pad of male rats, as the sex mismatch, to track the MSCs fate and to ensure their homing to the injured females' femurs. The isolated ASCs were characterized via the morphological appearance, multilineage potential and the PCR detection of CD29, CD44, CD106, CD14, CD34 and CD45 surface markers. Fifty adult female albino rats were enrolled in the current study. The rats were classified into five groups: group 1 was the gonad intact control, group 2 served as untreated ovariectomized (OVX) rats, group 3 was OVX rats treated with ASCs, group 4 was OVX rats treated with ASCs with injectable bone substitute (IBS) and group 5 was OVX rats treated with IBS. The serum levels of osteoprotegerin (OPG) and receptor activator of NF-к $\beta$ ligand (RANKL) were assayed using ELISA procedure. In addition, nuclear factor $-\kappa \beta(\mathrm{NF}-\kappa \beta)$ gene expression level was estimated in femur bones using real time -PCR. The isolated ASCs proved their MSCs identity via their morphological appearance and multilineage potential. In addition, the isolated ASCs showed positive expression for CD29, CD45, CD44 as well as CD106 and negative expression for CD34 and CD14. Besides, the positive expression of the Y-chromosome (sry) gene detected in the ASCs treated groups indicated that the systemically delivered single dose of undifferentiated ASCs was able to home at the females' femur bones. Adipose tissue derived mesenchymal stem cells (ASCs) injection with or without calcium phosphate composite in OVX rats reversed the effect of ovariectomy on the studied biomarkers causing significant increase in serum OPG level accompanied with significant decrease in serum RANKL level. Also, significant down regulation of NF- $\kappa \beta$ gene expression in femur bones was detected in the treated groups compared with untreated OVX group. These results clarified the good influence of ASCs against osteoclastogenesis. In addition the combination of ASCs injection with osteoinductive material injectable calcium phosphate composite (IBS), may be useful to achieve the significant antiosteoporotic effects.
\end{abstract}

\section{INTRODUCTION}

Osteoporosis is a systemic skeletal disease characterized by low bone mass and micro-architectural deterioration, with a consequent increase in bone fragility and susceptibility to fracture, particularly of the vertebral body, distal forearm and proximal femur of postmenopausal women. A recent practical definition of osteoporosis is based on bone mineral density (BMD). The BMD of the older person is compared to the average $\mathrm{BMD}$ of a person of the same gender at age 30 and the

\footnotetext{
* Corresponding Author

Hanaa H. Ahmed; E.mail: hanaaomr@yahoo.com.Tel. +202.33335966.
}

results expressed in standard deviation units, the so-called ' $\mathrm{T}$ score'. If the T-score is equal to or less than -2.5 then osteoporosis is diagnosed (Eastell, 2013). Osteoblast average survival has been shown to be a critical factor affecting the onset of postmenopausal osteoporosis. Under estrogen deficiency, there are more remodeling units and an unbalanced coupling of bone resorption and formation. This promotes increased rates of initiation of remodeling cycles and excess bone resorption, ultimately leading to lower overall bone density. By inhibiting apoptosis, estrogens may extend the life span of osteoblasts and thus enable bone formation to keep pace with bone resorption (Bradford et al., 2010). 
However the origin of postmenopausal osteoporosis was initially focused on osteoclastic activity and bone resorption; then on osteoblastogenesis and more recently on the differentiation potential of mesenchymal stem cells (MSCs) (Pino et al., 2012).

Mesenchymal stem cells are multipotent cells that are able to differentiate to osteoblasts, chondrocytes, and adipocytes and can be isolated from bone marrow, adipose tissue, and other mesodermal tissues (Yamachika and Iida, 2013).

In recent years, clinical trials with MSCs have taken the emerging field in many new directions. Expectations for patient benefits are high in these therapeutic applications. Nevertheless, the mechanism of action is not obvious (Trounson et al., 2011). However Fong et al., (2011) indicated a promising alternative is to reinforce the inherent reparative capacity of the body by delivering MSCs harvested from the patient's own tissues to the site of injury.

The various clinical trials demonstrate that fat-derived therapy is not a dream, but is becoming a reality. The efficiency of adipose tissue derived mesenchymal stem cells (ASCs) in regenerative medicine could be related more to their capacity to modulate immunity and/or inflammation than to their differentiation potentials. In this context, it is reasonable to suggest that, each time ASCs display effects more or less similar to other cell types, the inherent advantages of adipose tissue will favor its use over cells from other sources (Casteilla et al., 2011).

The current study was designed to evaluate the influence of adipose tissue derived mesenchymal stem cells (ASCs) singly or in combination with calcium phosphate composite on osteoclastogenesis in ovariectomized rats.

\section{MATERIALS AND METHODS}

\section{Isolation and preparation of ASCs}

Adipose tissue was excised from both the omentum (i.e., abdominal) and the inguinal fat pad (i.e., subcutaneous) of male albino rats under general anesthesia according to Tomiyama et al., (2008).

The adipose tissue was resected and placed into a labeled sterile tube containing $15 \mathrm{~mL}$ of a phosphate buffered solution (PBS; Gibco/Invitrogen, Grand Island, New York, USA). Enzymatic digestion was performed using $0.075 \%$ collagenase II (Serva Electrophoresis GmbH, Mannheim) in Hank's Balanced Salt Solution for $60 \mathrm{~min}$ at $37^{\circ} \mathrm{C}$ with shaking.

Digested tissue was filtered and centrifuged, and erythrocytes were removed by treatment with erythrocyte lysis buffer. The cells were transferred to tissue culture flasks with Dulbecco modified eagle medium (DMEM, Gibco/BRL, Grand Island, New York, USA) supplemented with $10 \%$ fetal bovine serum (FBS, Gibco/BRL) and, after an attachment period of 24 hours, non-adherent cells were removed by a PBS wash. Attached cells were cultured in DMEM media supplemented with $10 \%$ fetal bovine serum, $1 \%$ penicillin-streptomycin (Gibco/BRL), and $1.25 \mathrm{mg} / \mathrm{L}$ amphotericin $\mathrm{B}$ (Gibco/BRL), and expanded in vitro. When large colonies of ASCs developed (80-90\% confluence), cultures were washed twice with phosphate buffer saline (PBS) and the cells were trypsinized with $0.25 \%$ trypsin in $1 \mathrm{mM}$ EDTA (GIBCO/BRL) for $5 \mathrm{~min}$ at $37{ }^{\circ} \mathrm{C}$. After centrifugation, cells were resuspended with serum-supplemented medium and incubated in $50 \mathrm{~cm}^{2}$ culture flask (Falcon). The resulting cultures were referred to as first-passage cultures (Alhadlaq and Mao, 2004).

To ensure the MSCs identity, the cells were characterized morphologically by inverted microscope examination. Additionally, multilineage potential was confirmed via in vitro differentiation to adipocytes, chondrocytes and osteocytes. Furthermore, PCR detection of CD29, CD44, CD106, CD14, CD34 and CD45 genes expression were done also.

\section{In vitro differentiation of ASCs}

Adipose tissue derived cells were grown until confluence and the growth medium was replaced with the inductive medium consisting of Iscove's modified Dulbecco's medium (Invitrogen, USA), $20 \%$ fetal calf serum, $100 \mathrm{U} / \mathrm{mL}$ penicillin, $100 \mu \mathrm{g} / \mathrm{mL}$ streptomycin and $0.05 \mathrm{mM} \beta$-mercaptoethanol supplemented with specific differentiation reagents as follows:

\section{Adipogenesis assay}

Cells were incubated for 3 weeks with $5 \mu \mathrm{g} / \mathrm{mL}$ insulin (Sigma, USA) and $10^{-9} \mathrm{M}$ dexamethasone. Adipogenic differentiation was visualized in phase-contrast microscopy by the presence of highly refractive intracellular lipid vacuoles (Rombouts and Ploemacher, 2003). Oil Red O (Sigma, USA) staining was used to assay the accumulation of lipid droplets in these vacuoles.

\section{Chondrogenesis assay}

The stem cells were harvested and $6 \times 10^{5}$ cells were centrifuged to form a pellet on the bottom of a $15 \mathrm{~mL}$ polypropylene tube (Falcon). The micro mass was cultured in 500 $\mu \mathrm{L}$ of chondrogenic medium that consisted of $50 \mu \mathrm{g} / \mathrm{mL}$ ascorbic acid 2-phosphate and $1 \mathrm{ng} / \mathrm{mL}$ TGF- $\beta 1$ (Sigma, USA) (Peister et al., 2004).

After 3 weeks of culture, cell clumps were harvested, embedded in paraffin, cut into $3 \mu \mathrm{m}$ sections, and stained for glycosaminoglycans using 0.1\% Alchian blue (Sigma, USA).

\section{Osteogenesis assay}

Stem cell cultures were fed twice a week for 3 weeks with $10 \mathrm{mM} \beta$-glycerophosphate, $50 \mu \mathrm{g} / \mathrm{mL}$ ascorbic acid 2phosphate and 10-9 M dexamethasone (Phinney et al., 1999). Then cells were fixed with $10 \%$ formalin for $20 \mathrm{~min}$ at room temperature and mineralization (presence of calcium-rich hydroxyapatite) of the extracellular matrix was assessed by staining for $20 \mathrm{~min}$ with $2 \% \mathrm{wt} / \mathrm{vol}$ Alizarin Red S, adjusted to $\mathrm{pH}$ 4.1 with ammonium hydroxide ((Peister et al., 2004), all reagents were obtained from Sigma, USA. 
PCR detection of CD14, CD29, CD34, CD44, CD45 and CD106 genes expression

RNA extraction from MSCs

In order to confirm that the isolated cells from adipose tissues are mesenchymal stem cells, total RNA was extracted from cultured cells using RNeasy mini kit for purification of total RNA from animal cells (Qiagen, Germany) according to the manufacturer's instructions.

\section{Reverse transcription}

The reverse transcription was carried out on the extracted RNA $(1 \mu \mathrm{g})$ using the high capacity cDNA reverse transcription kit (Applied Biosystems, USA) according to the manufacturer's instructions.

\section{Conventional PCR detection of CD29, CD34 and CD45 genes} expression

The conventional PCR reaction mix for CD29, CD34 and CD45 was $12.5 \mu \mathrm{L}$ of master mix (Qiagen, Germany), $1 \mu \mathrm{L}$ of forward primer $(10 \mathrm{pmol} / \mu \mathrm{L}), 1 \mu \mathrm{L}$ of reverse primer (10 $\mathrm{pmol} / \mu \mathrm{L}$ ) (Invitrogen, Germany) (Table 1), $5 \mu \mathrm{L}$ cDNA and 5.5 $\mu \mathrm{L}$ nuclease free water. PCR was performed using the thermal cycler instrument, Biometra T professional, (USA) for 35 cycles with initial denaturation step at $94^{\circ} \mathrm{C}$ for $3 \mathrm{~min}$ for CD29 as well as CD45 and for $2 \mathrm{~min}$ for CD34. Each cycle consisting of denaturation at $94{ }^{\circ} \mathrm{C}$ for $30 \mathrm{~s}$, annealing at $57{ }^{\circ} \mathrm{C}$ for CD29 as well as CD45 and at $55^{\circ} \mathrm{C}$ for $\mathrm{CD} 34$ for $30 \mathrm{~s}$, elongation at $72{ }^{\circ} \mathrm{C}$ for 1 min followed by $7 \mathrm{~min}$ of terminal extension at $72{ }^{\circ} \mathrm{C}$ after completion of the last cycle. The PCR product was separated by electrophoresis through a $1 \%$ agarose gel, stained, and photographed under ultraviolet light.

Table. 1: Primers sequences of the studied genes used for PCR.

\begin{tabular}{|c|c|}
\hline Genes & Primers sequences \\
\hline \multirow{4}{*}{ CD14 } & Forward: 5'-GTGTGAGTGGTAGCCAGCAA-3' \\
\hline & Reverse: 5'-TGCGCAGCGCTAAAACTTG-3', according to \\
\hline & Schäfer et al., (2012) published sequence. \\
\hline & Forward: 5'-AATGTTTCAGTGCAGAGC-3' \\
\hline CD29 & Reverse: 5'- TTGGGATGATGTCGGGAC-3', according to \\
\hline & Wang et al., (2004) published sequence. \\
\hline \multirow{3}{*}{ CD34 } & Forward: 5'-GCCCAGTCTGAGGTTAGGCC-3' \\
\hline & Reverse: 5'- ATTGGCCTTTCCCTGAGTCT-3', according to \\
\hline & Qin et al., (2011) published sequence. \\
\hline \multirow{3}{*}{ CD44 } & Forward: 5'- TTGGCATCCCTCCTGGCGCTGG -3' \\
\hline & $\begin{array}{l}\text { Reverse: 5'- AAGGAGGAACTGGAAGAGACCC-3', } \\
\text { according to Qin } \text { et al., (2011) published sequence. }\end{array}$ \\
\hline & Forward: 5'-ACCAGGGGTTGAAAAGTTTCAG-3' \\
\hline \multirow[t]{3}{*}{ CD45 } & Reverse: 5'-GGGATTCCAGGTAATTACTCC-3', according to \\
\hline & Muñoz-Fernández et al., (2006) published sequence. \\
\hline & Forward: 5'-CCTCACTTGCAGCACTACGGGCT-3' \\
\hline CD106 & $\begin{array}{l}\text { Reverse: } 5 \text { '- TTTTCCAATATCCTCAATGACGGG-3', } \\
\text { according to Lau and Bhatia (2007) published sequence. }\end{array}$ \\
\hline & Forward: 5'- CAAGGTCATCCATGACAACTTTG -3' \\
\hline GAPDH & $\begin{array}{l}\text { Reverse: 5'- GTCCACCACCCTGTTGCTGTAG -3', according } \\
\text { to Schäfer } \text { et al., (2012) published sequence. }\end{array}$ \\
\hline
\end{tabular}

Real time PCR detection of GAPDH, CD14, CD44 and CD106 genes expression

The real time PCR was peformed using the QuantiTect SYBR green PCR Kit (Qiagen, Germany) according to the manufacturer's instructions, by Applied Biosystems 7500 Instrument, USA. The real time PCR reaction mix was carried out in a total volume of $25 \mu \mathrm{L}$, containing $12.5 \mu \mathrm{L}$ of $2 \times$ QuantiTect SYBR green PCR master mix, $0.5 \mu \mathrm{L}$ of forward primer for GAPDH (20 pmol $/ \mu \mathrm{L}), 0.5 \mu \mathrm{L}$ of reverse primer for GAPDH (20 $\mathrm{pmol} / \mu \mathrm{L}$ ) (Table 1$), 4 \mu \mathrm{L}$ cDNA and $7.5 \mu \mathrm{L}$ nuclease free water.

The real time PCR reaction mix for CD14 was $12.5 \mu \mathrm{L}$ of 2 x QuantiTect SYBR green PCR master mix, $1 \mu \mathrm{L}$ of forward primer $(10 \mathrm{pmol} / \mu \mathrm{L}), 1 \mu \mathrm{L}$ of reverse primer $(10 \mathrm{pmol} / \mu \mathrm{L})($ Table 1), $4 \mu \mathrm{L}$ cDNA and $6.5 \mu \mathrm{L}$ nuclease free water. While, the reaction mix for CD44 and 106 were $12.5 \mu \mathrm{L}$ of 2 x QuantiTect SYBR green PCR master mix, $1 \mu \mathrm{L}$ of the corresponding forward primer (10 pmol/ $/ \mu \mathrm{L}), 1 \mu \mathrm{L}$ of the corresponding reverse primer (10 $\mathrm{pmol} / \mu \mathrm{L}$ ) (Table 1), $3 \mu \mathrm{L}$ cDNA and $7.5 \mu \mathrm{L}$ nuclease free water.

The protocol consisted of 45 amplification cycles, each conducted as follows: $10 \mathrm{~min}$ at $95^{\circ} \mathrm{C}$ (holding stage), $15 \mathrm{sec}$ for denaturation at $95^{\circ} \mathrm{C}, 30 \mathrm{sec}$ for annealing at $60^{\circ} \mathrm{C}$ and another 15 sec for elongation at $60^{\circ} \mathrm{C}$.

\section{Biomaterials}

Injectable bone substitute (IBS) is a composite biomaterial obtained by associating a polymer and biphasic calcium phosphate (BCP) granules $(40 \% \mathrm{w} / \mathrm{v})$. BCP granules contained $60 \%$ hydroxy apatite (HA) (Sigma-Aldrich Co., USA), $40 \%$ tricalcium phosphate ( $\beta$-TCP) (Merck KGaA Co, Germany). The polymer is a cellulose derivative (hydroxy-propyl-methylcellulose - HMPC) (Winlab Co., U.K). An aqueous solution of 3\% HPMC was prepared by dissolving raw, dry HPMC powder in bidistilled water under stirring for $48 \mathrm{~h}$. BCP granules were added under stirring and the biomaterial was prepared in ready-to-use glass flasks sterilized by steam at $121^{\circ} \mathrm{C}$ for $20 \mathrm{~min}$ (Blouin et al., 2006). Then the IBS was transferred into $1 \mathrm{ml}$ syringe mounted with $18 \mathrm{G}$ needle and injected submuscular adjacent to the femur surface. Each rat was injected with two IBS doses $(640 \mu \mathrm{l}$ each) one for each femur (Trojani et al., 2006).

\section{Experimental animals}

Adult female albino rats weighing 130-150 g were obtained from the Animal House Colony of the National Research Centre, Cairo, Egypt, and acclimated for one week in a specific area where temperature $\left(25 \pm 1^{\circ} \mathrm{C}\right)$ and humidity $(55 \%)$. Rats were cared for according to the guidelines for Animal Experiments which were approved by the Ethical Committee of Medical Research at National Research Centre, Cairo, Egypt. Experimental osteoporosis was induced in the adult female rats surgically by ovariectomy. Under general anaesthesia using diethyl ether, the rats were bilaterally ovariectomized by dorsal approach (Mattila, 1999). The surgical ovariectomy operation was performed at Hormones Department, Medical Research Division, National Research Centre. Ovariectomized (OVX) rat is a suitable experimental model for postmenopausal osteoporosis that faithfully reproduces the changes observed in human subjects and has an additional benefit that the effects are detectable only a few 
months after intervention (D1'az-Curiel and Gala, 1994). This study included 50 adult female rats, which were divided into 5 experimental groups (10 rats/group) as follows after three months from the surgical ovariectomy: Group I (Gonad intact group): healthy female rats as negative control group, Group II (OVX group): untreated ovariectomized rats, Group III (ASCs group): ovariectomized rats infused with a single dose of undifferentiated adipose derived MSCs $\left(3 \times 10^{6}\right.$ cells/rat) intravenously (Nakamura et al., 2000; Zhao et al., 2005), Group IV (ASCs and IBS group): ovariectomized rats infused with a single dose of undifferentiated adipose derived MSCs $\left(3 \times 10^{6}\right.$ cells/rat $)$ intravenously and injected with IBS sub muscularly adjacent to the femur surface and Group $\boldsymbol{V}$ (IBS group): ovariectomized rats injected with IBS sub muscularly adjacent to the femur surface.

At the end of the experimental period, after three months of MSCs transplantation and IBS injection, all animals were fasted for $12 \mathrm{~h}$ and the blood samples were collected from retro-orbital venous plexus (Schermer, 1967) under diethyl ether anaesthesia. The blood samples were left to clot and the sera were separated by cooling centrifugation $\left(4^{\circ} \mathrm{C}\right)$ at $1800 \mathrm{xg}$ for $10 \mathrm{~min}$ and then stored immediately at $-80^{\circ} \mathrm{C}$ till analysis. While the rats' femur bones were immediately dissected, carefully cleaned and frozen in liquid nitrogen, then stored at $-80{ }^{\circ} \mathrm{C}$ for the molecular genetics analysis of nuclear factor- $\kappa \beta$.

\section{PCR detection of male-derived MSCs in femur bones of treated females}

The genomic DNA was prepared from femur bones of female rats treated with ASCs using Wizard $^{\circledR}$ Genomic DNA purification kit (Promega, Madison, WI, USA). The presence or absence of the sex determination region on the $\mathrm{Y}$ chromosome male (sry) gene in the femur bones of recipient female rats was assessed by quantitative PCR. Primer sequences for sry gene (forward 5'-CAT CGAAGGGTTAAAGTGCCA-3', reverse 5'ATAGTGTGTAG-GTTGTTGTCC-3') were obtained from the previous published sequences (Wu et al., 2003) and amplified to a product of $104 \mathrm{bp}$. The PCR conditions were as follows: incubation at $94{ }^{\circ} \mathrm{C}$ for $4 \mathrm{~min} ; 35$ cycles of incubation at $94{ }^{\circ} \mathrm{C}$ for $50 \mathrm{~s}, 60^{\circ} \mathrm{C}$ for $30 \mathrm{~s}$, and $72{ }^{\circ} \mathrm{C}$ for $1 \mathrm{~min}$; with a final incubation at $72{ }^{\circ} \mathrm{C}$ for $10 \mathrm{~min}$. PCR products were separated using $2 \%$ agarose gel electrophoresis and stained with ethidium bromide.

\section{Biochemical analyses}

Serum osteoprotegerin (OPG) and receptor activator of NF-к $\beta$ ligand (RANKL) levels were assayed by ELISA technique using kits purchased from Glory Science Co., USA, according to the manufacturer's instructions.

\section{Molecular genetics analysis of nuclear factor- $\kappa \beta$ gene expression using real time PCR \\ RNA extraction}

Total RNA was isolated from femur bones of female rats using SV Total RNA Isolation system (Promega, Madison, WI, USA) according to manufacturer's instruction. The RNA sample was dissolved in RNase-free water and quantified spectrophotometrically, then the concentration of the RNA was assayed using the OD 260/280 ratio, and only samples with ratios above 1.5 were used in the experiments.

cDNA synthesis

First-strand cDNA synthesis was performed with the SuperScript Choice System (Life Technologies, Breda, Netherlands) by mixing $2 \mu \mathrm{g}$ total RNA with $0.5 \mu \mathrm{g}$ of oligo (dT) $12-18$ primer in a total volume of $12 \mu \mathrm{L}$. After heating the mixture at $70^{\circ} \mathrm{C}$ for $10 \mathrm{~min}$, a solution containing $50 \mathrm{mmol} / \mathrm{L}$ Tris $\mathrm{HCl}$ ( $\mathrm{pH} 8.3$ ), $75 \mathrm{mmol} / \mathrm{L} \mathrm{KCl}, 3 \mathrm{mmol} / \mathrm{L} \mathrm{MgCl} 2,10 \mathrm{mmol} / \mathrm{L}$ DTT, $0.5 \mathrm{mmol} / \mathrm{L}$ dNTPs, $0.5 \mu \mathrm{L}$ RNase inhibitor, and $200 \mathrm{U}$ Superscript Reverse Transcriptase was added, resulting in a total volume of $20.5 \mu \mathrm{L}$. This mixture was incubated at $42^{\circ} \mathrm{C}$ for $1 \mathrm{~h}$.

\section{Real-time quantitative polymerase chain reaction (PCR)}

For real-time quantitative PCR, $5 \mu \mathrm{L}$ of first-strand cDNA was used in a total volume of $25 \mu \mathrm{L}$, containing $12.5 \mu \mathrm{L}$ 2x SYBR Green PCR Master Mix (Applied Biosystems, Foster City, CA, USA) and $200 \mathrm{ng}$ of each primer (shown in Table 2). PCR reactions consisting of $95^{\circ} \mathrm{C}$ for $10 \mathrm{~min}(1 \mathrm{cycle}), 94^{\circ} \mathrm{C}$ for $15 \mathrm{~s}$, and $60^{\circ} \mathrm{C}$ for $1 \mathrm{~min}$ (40 cycles), were performed on an ABI Prism 7900 HT Fast Real Time PCR system (Applied Biosystems). Data were analyzed with the ABI Prism 7500 sequence detection system software and quantified using version 1.7 Sequence Detection Software from PE Biosystems (Foster City, CA). Relative expression of studied genes was calculated using the comparative threshold cycle method. All values were normalized to the beta actin genes (Livak and Schmittgen, 2001).

Table. 2: Primers sequences of the studied genes used for real-time PCR.

\begin{tabular}{clcc}
\hline Genes & \multicolumn{3}{c}{ Primers sequences } \\
\hline \multirow{3}{*}{ NF- $\kappa \beta$} & Forward: 5 5'-ACG ATC TGT TTC CCC TCA TC-3' & Reverse: $5^{\prime}-$ TGC TTC TCT CCC CAG GAA TA-3', according to \\
& Zhu et al., (2008) published sequence. \\
& Forward: 5'-TCT GGC ACC ACA CCT TCTACAATG-3' \\
R-actin & Reverse: $5^{\prime}$ - AGC ACA GCC TGG ATA GCA ACG -3', according to \\
& Porichi et al., (2009) published sequence. \\
\hline
\end{tabular}

\section{Statistical analyses}

In the present study, all results were expressed as Mean \pm S.E of the mean. Data were analyzed by one way analysis of variance (ANOVA) using the Statistical Package for the Social Sciences (SPSS) program, version 17 followed by least significant difference (LSD) to compare significance between groups (Armitage and Berry, 1987). Difference was considered significant when $P$ value was $<0.05$.

\section{RESULTS}

\section{Stem cells morphology}

The photomicrographs in Fig. (1) show the shape of the ASCs at the first day of isolation and culture (Fig. 1a) and the spindle shape of cells which is the typical morphological aspects 
of mesenchymal stem cells derived from adipose tissue through culture flask at day 10 (Fig. 1b) and day 14 (Fig.1c).



A



C



B
Fig. 1: Morphological aspects of ASCs in culture flask.

\section{In vitro differentiation of ASCs}

\section{Adipogenic differentiation}

Adipose derived stem cells are differentiated into adipocytes through 1 week of culture (Fig. $2 \mathbf{b}$ ) and continued to increase in cells number through 2 weeks of culture (Fig. 2c). Adipocytes are stained with special Oil Red O stain (Fig. 2d).
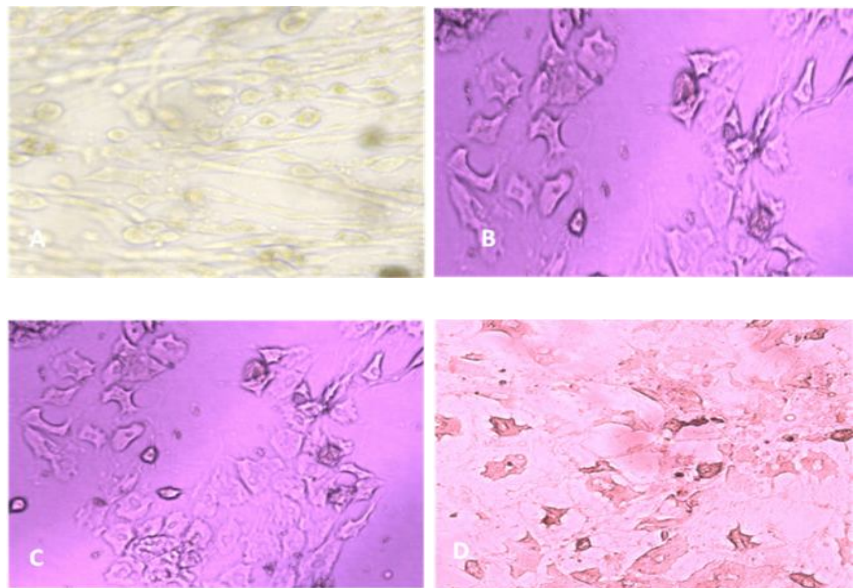

Fig. 2: Differentiation of ASCs into adipocytes. (a): Undifferentiated adipose derived MSCs at 2 weeks in culture; (b): Adipose derived MSCs at 1 week of differentiation into adipocytes; (c): Adipose derived MSCs at 2 weeks of differentiation into adipocytes; (d): Differentiated ASCs into adipocytes stained with special Oil Red O stain

\section{Chondrogenic differentiation}

Adipose derived stem cells are differentiated through 1 week into chondrocytes (Fig. 3b), as indicated by their round configuration and the development of an extracellular matrix that stained with special Alchian blue stain (Figs. 3c and 3d).

\section{Osteogenic differentiation}

Adipose derived stem cells are differentiated into osteocytes through 1 week of culture (Fig. 4b). The osteocytes are stained with special Alizarin Red S stain (Figs. 4c and 4d).
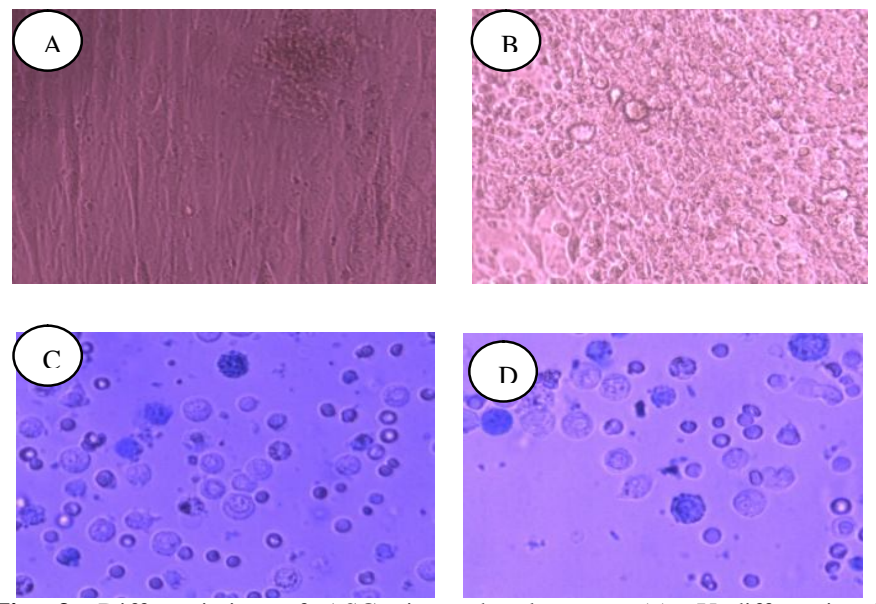

Fig. 3: Differentiation of ASCs into chondrocytes. (a): Undifferentiated adipose derived MSCs at 2 weeks in culture; (b): Adipose derived MSCs at 1 week of differentiation into chondrocytes; (c and d): Differentiated ASCs into chondrocytes stained with special Alchian blue stain.
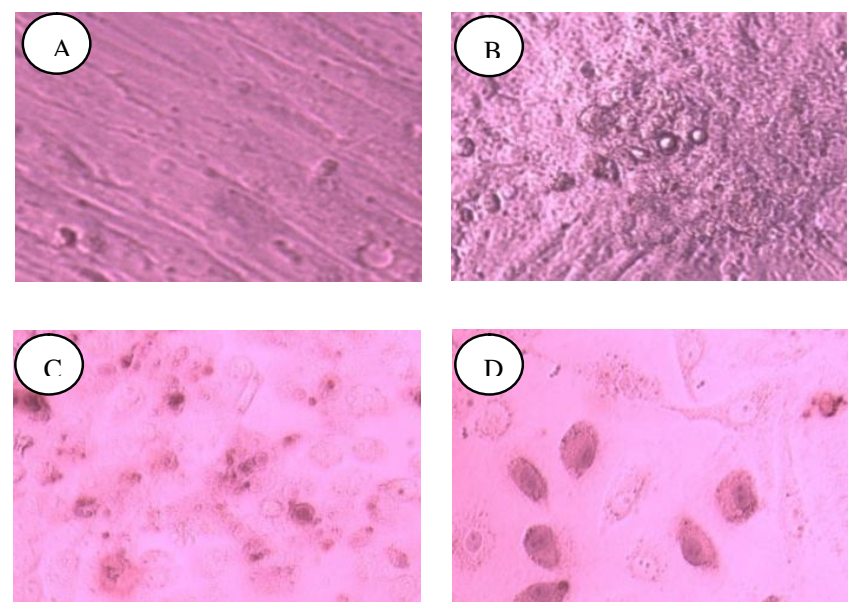

Fig. 4: Differentiation of ASCs into osteocytes. (a): Undifferentiated adipose derived MSCs at 2 weeks in culture; (b): Adipose derived MSCs at 1 week of differentiation into osteocytes; (c and d): Differentiated ASCs into osteocytes stained with special Alizarin Red S stain.

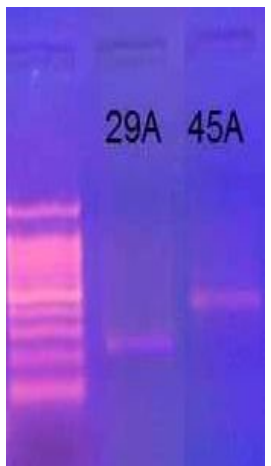

Fig. 5: Agarose gel electrophoresis for $\mathrm{CD} 29$ and $\mathrm{CD} 45$ genes expression for ASCs sample. Lane (1) represented DNA ladder, lane (2) represented CD29 gene expression and lane (3) represented CD45 gene expression.

\section{Cell surface markers for ASCs}

The agarose gel electrophoresis shows that ASCs used in the present study are positive for CD29 and CD45 genes expression as the positive bands appear at 261and $343 \mathrm{bp}$ respectively (Fig. 5). Moreover, the agarose gel electrophoesis in 
Fig. (6) showed that the used ASCs are negative for CD34 gene expression.

The amplification plots of the real time PCR for CD14, CD44 and CD106 show that the ASCs used in the present study are negative for CD14 gene expression and positive for CD44 as well as CD106 genes expression (Figs. 7 and 8 respectively). The data given in Fig. (8) indicated that the expression of CD44 exceeds the threeshold which is equal 1.733. While, the expression of CD106 exceeds the threeshold which is equal 2.313 .



Fig. 6: Agarose gel electrophoresis for CD34 gene expression for ASCs sample. Lane (1) represented DNA ladder, lane (2) represented CD34 gene expression.

\section{Mesenchymal stem cells homing (PCR detection of male-derived MSCs)}

The bones of femur from untreated OVX rats show negative expression of sry gene as shown in agarose gel electrophoresis from DNA fragments. While those represent the bones of femur of OVX rats treated with ASCs show positive expression of sry gene (Fig. 9). These results confirm the homing of the male donor stem cells to the injured femur bones of the female recipients.

\section{Biochemical and Molecular genetics analyses}

The data in Table (3) represent the effect of ASCs therapy with or without IBS as well as IBS injection alone on serum OPG and RANKL levels in OVX rats. The data indicated that serum OPG level decreased significantly in the OVX group (50.3\%) in comparison with the gonad intact control group. On the other hand, ASCs and ASCs with IBS groups significantly increased serum OPG level as compared to the OVX group with a percent of change $23.1 \%$ and $30.4 \%$ respectively.

Regarding the alterations in serum RANKL level following ASCs infusion with or without IBS and IBS injection alone, the OVX group recorded significant increase $(44.1 \%)$ in serum RANKL level when compared to the gonad intact control group. However, the all treated groups showed significant decrease in serum RANKL level as compared to the OVX group. The percent of changes of the decreased RANKL levels were - $16.4 \%$ for ASCs, $-17.6 \%$ for ASCs + IBS and $-10.5 \%$ for IBS.

The alterations in $\mathrm{NF}-\kappa \beta$ gene expression level in femur bones following ASCs injection with or without IBS as well as IBS injection alone are shown in Table (4). The data illustrated that NF-к $\beta$ gene expression level increased significantly in the OVX group (110.3\%) with respect to the gonad intact control group. In the contrary, NF-к $\beta$ gene expression level decreased significantly in ASCs, ASCs with IBS and IBS treated groups as compared to OVX group with the percent of change $-29.9 \%$, $35.2 \%$ and $-16.6 \%$ respectively.

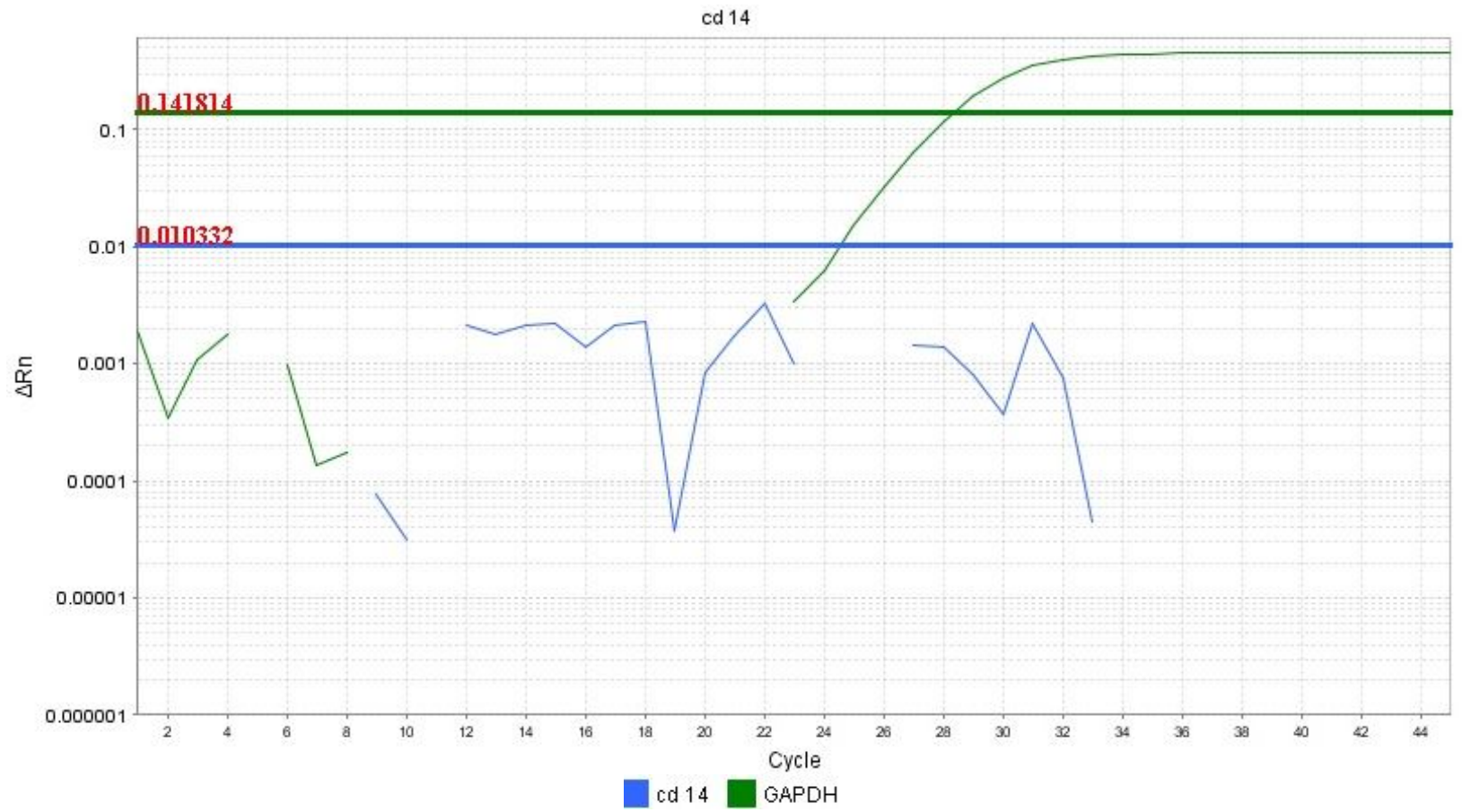

Fig. 7: The real time PCR amplification plot for CD14 gene for the ASCs sample. 




Fig. 8: The real time PCR amplification plot for CD44 and CD106 genes for the ASCs sample.

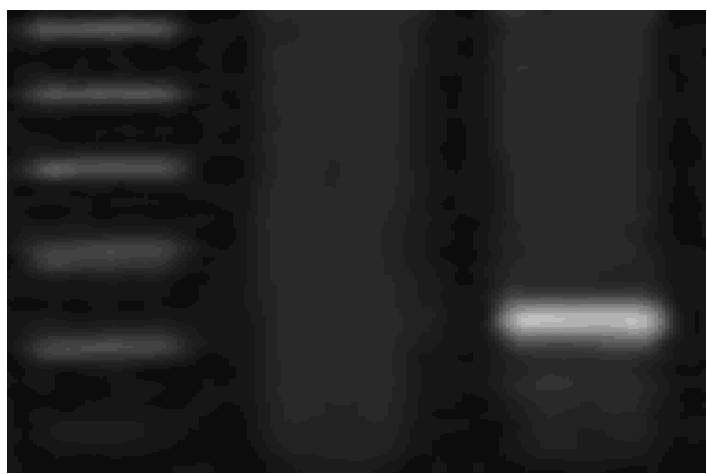

Fig. 9: Agarose gel electrophoresis of DNA fragments shows sry gene in recipient female rats for ASCs. (M): represents DNA ladder; Lane (1): represents untreated OVX rat sample; Lane (2): represents sample from OVX rat treated with ASCs.

Table. 3: Effect of ASCs therapy with or without IBS as well as IBS alone on serum OPG and RANKL levels in OVX rats. Data are represented as Mean \pm S.E of 10 rats /group.

\begin{tabular}{lcc}
\hline \multicolumn{1}{c}{ Groups } & OPG & RANKL \\
$(\mathbf{p g} / \mathbf{m l})$ & \\
\hline Gonad intact control & $(\mathbf{p g} / \mathbf{m l})$ & $66.69 \pm 1.97$ \\
OVX & $13.89 \pm 0.31$ & $96.13 \pm 1.59^{\mathrm{a}}$ \\
OVX + ASCs & $6.9 \pm 0.26^{\mathrm{a}}$ & $80.38 \pm 1.02^{\mathrm{b}}$ \\
OVX + ASCs + IBS & $8.56 \pm 0.27^{\mathrm{b}}$ & $79.15 \pm 1.07^{\mathrm{b}}$ \\
OVX + IBS & $9.04 \pm 0.51^{\mathrm{b}}$ & $86.01 \pm 1.89^{\mathrm{bcd}}$ \\
\hline
\end{tabular}

a: Significant change at $\mathrm{P}<0.05$ in comparison with gonad intact group. b: Significant change at $\mathrm{P}<0.05$ in comparison with the osteoporotic group. c: Significant change at $\mathrm{P}<0.05$ in comparison with the ASCs treated group. d: Significant change at $\mathrm{P}<0.05$ in comparison with the ASCs+IBS treated group.

Table. 4: Effect of ASCs therapy with or without IBS as well as IBS alone on NF- $\kappa \beta$ gene expression level in femur bones of OVX rats. Data are represented as Mean \pm S.E of 10 rats /group

\begin{tabular}{lcc}
\hline \multicolumn{1}{c}{ Groups } & NF-k $\boldsymbol{\beta}$ Relative expression \\
\hline Gonad intact control & $1.54 \pm 0.07$ \\
OVX & $3.24 \pm 0.13^{\mathrm{a}}$ \\
OVX + ASCs & $2.2 \pm 0.10^{\mathrm{b}}$ \\
OVX + ASCs + IBS & $2.0 \pm 0.10^{\mathrm{b}}$ \\
OVX + IBS & $2.7 \pm 0.08^{\mathrm{bcd}}$ \\
\hline
\end{tabular}

a: Significant change at $\mathrm{P}<0.05$ in comparison with gonad intact group. b: Significant change at $\mathrm{P}<0.05$ in comparison with the osteoporotic group.

c: Significant change at $\mathrm{P}<0.05$ in comparison with the ASCs treated group. d: Significant change at $\mathrm{P}<0.05$ in comparison with the ASCs+IBS treated group. 


\section{DISCUSSION}

'To do no harm' is the basic tenet of medical practice. The importance of this mantra is especially true in the development of any experimental treatment. Theoretically, stem cells may exert beneficial functional effects by replacing lost or damaged cells (Rice and Scolding, 2008). Yet, in vivo, how they exercise auto specific function is not fully understood (Song et al., 2013). The present study used the sex mismatched model and postulated that the male ASCs may be able to migrate and home to the females' femur bones and affect ovariectomy induced osteoclastogenesis in these adult female rats.

The confirmatory results for ASCs properties indicated their adhesiveness and fusiform shape in culture flask and these findings are in agreement with those of Rochefort et al., (2005). Also, isolated ASCs had the ability to differentiate into adipocytes, chondrocytes and osteocytes as defined by Pittenger et al., (1999). Moreover, the PCR results demonstrated that the isolated ASCs were positive for CD29, CD45 and CD106 and these results are greatly supported by those of Li et al., (2010). While the negativity for CD34 is in agreement with that of Ren et al., (2011). Our findings showed that ASCs are positive for CD 44 and negative for CD14. These results are in consistent with those of Ying et al., (2012) and Sachs et al., (2012) who reported similar findings for adipose derived mesenchymal stem cells. Meanwhile, the positive expression of sry gene in the femur bones of ovariectomized rats treated with ASCs confirmed the migration capacity of the intravenously infused ASCs to the site of injury. This property could be attributed to the chemokines, cytokines, and growth factors released upon injury and provided migratory cues for systemically or locally administered stem cells. These cues induce upregulation of selectins and activation of integrins on the stem cell surface, enabling cells to interact with the endothelium. Stem cells subsequently adhere and transmigrate across the endothelial layer into tissues (Kang et al., 2012).

Ovariectomized animals represent an optimal model to investigate osteoclastogenesis in osteoporosis. Ovariectomy greatly influences expression of various genes involved in diverse biological processes confirming the notion that numerous pathways play an important role in pathophysiology of osteoporosis (Orlić et al., 2007). To determine the difference between the osteoporotic and normal groups in terms of osteoclastic and osteoblastic activation, serum OPG and RANKL levels were analyzed. The results showed significant decrease in serum OPG level in concomitant with significant increase in serum RANKL level in the OVX group as compared to gonad intact control group. The results of the different previous works concerning estrogen and its interaction with the OPG/RANKL pathway are not conflicting because estrogen has been shown to stimulate OPG secretion and also to down regulate the expression of RANKL (Trouvin and Goëb, 2010). Hence, in postmenopausal females as well as in ovariectomized one as the production of estrogen is reduced, subsequently the production of OPG is hindered and postmenopausal osteoporosis sets in. Our results come in parallel with Dalle Carbonare et al., (2009) who found that RANKL levels increased in patients with osteoporosis and associated with a lower OPG/ RANKL ratio.

The initial evidence to support the relationship between estrogen and RANKL comes from animal models in which ovariectomized rats were shown to have elevated RANKL levels (Miyazaki et al., 2004). Similar results were observed by Zhang et al., (2009) in studying RANKL levels in OVX rats, also several reports provided further credence to the theory that estrogen deficiency results in increased osteoclastogenesis secondary to increased production of TNF- $\alpha$ and RANKL (D'Amelio et al., 2008 and Anandarajah, 2009). These two studies support the notion that estrogen deficiency in postmenopausal women and in ovariectomized animals results in increased RANKL level, leading to increased osteoclastic activity that in turn increases bone resorption and the risk for osteoporotic fractures.

RANKL is required for all stages of osteoclast differentiation, beginning with the commitment to all the lineage, and also it stimulates the resorptive activity of mature cells. In addition mice lacking RANKL or its receptor make no osteoclasts. Given that RANKL induces activation of several pathways shown to be necessary for osteoclastogenesis in vitro, it is quite intriguing that the constitutive activation of $N F-\kappa B$ is sufficient to mediate osteoclast differentiation (Novack, 2011). Binding of RANKL to the RANK receptor leads to subsequent NF- $\kappa \beta$-mediated induction of osteoclast differentiation genes, prolonged survival of osteoclast and increased bone resorption (Krum et al., 2010).

The OPG/RANKL ratio is considered to better reflect the bone remodeling environment signs. A high ratio represents bone formation while a low ratio favors bone resorption (Silva and Branco, 2011). Evidence that OPG acts as an inhibitor of osteoclastogenesis has emerged from experiments with transgenic mice, in which over expression of OPG led to severe osteopetrosis and reduced the number of mature osteoclasts. In contrast, mice lacking the gene for OPG are osteoporotic (Dalle Carbonare et al., 2009). The biological effects of OPG include inhibition of the terminal stages of osteoclast differentiation and suppression of mature osteoclast activation (Kobayashi et al., 2009) by blocking the RANKL/RANK interaction which activates the osteoclast formation (Sherman, 2012). So as the competitive inhibition by OPG is stalled, the production of RANKL is increased which leads to the formation of RANKL-RANK complex, as part of the counterbalancing phenomenon. Finally this leads to greater bone resorption and decrease in bone mineral density (Silva and Branco, 2011). Studies performed on ovariectomized rat models lend credibility to this theory as ovariectomy is known to disturb the balance between bone formation and bone resorption (Cardemil et al., 2013). More in detail Ominsky et al., (2008) have reported that ovariectomy in rats was associated with high levels of serum RANKL and also showed that OPG reduces osteoclast surface and prevents ovariectomy-associated bone loss in femur.

NF- $\kappa \beta$ signaling plays essential roles in certain aspects of osteoclast, osteoblast activities and it is activated in a number of pathologic conditions affecting the skeleton, including postmenopausal osteoporosis (Boyce et al., 2010). Our results 
indicated a significant increase of $\mathrm{NF}-\kappa \beta$ gene expression level in OVX rats compared with that in the gonad intact control group. This finding comes in line with previously reported data that the local expression level of $N F-\kappa \beta$ increased significantly in a time dependent manner in the bone tissue of osteoporotic rats, and it could play a role in the pathogenesis of osteoporosis (Zhu et al., 2008). Also, this result agrees, with Chang et al., (2009) who showed an increase in NF- $\kappa \beta$ activity in ovariectomy and evidenced that estrogen regulates $\mathrm{NF}-\kappa \beta$ in osteoblasts in vivo. The activation of NF- $\kappa \beta$ due to estrogen deficiency not only promotes osteoclast activation, osteoclast survival and bone resorption, but simultaneously inhibits osteoblast function (Krum et al., 2010). Historically, NF- $\kappa \beta$ has not been considered as a key mediator of osteoblast signaling, but several studies have shown that $\mathrm{NF}-\kappa \beta$ inhibits both osteoblast differentiation and activity. Yamazaki et al., (2009) demonstrated that NF- $\kappa \beta$ can interact with the Smad1Smad5 complex in the nucleus and disrupt its binding to target promoters. NF- $\kappa \beta$ blocks the induction of Runx-2 by SMAD, resulting in the inhibition of osteoblast differentiation (Novack, 2011).

The altered serum levels of OPG and RANKL, besides the significant down regulation of $\mathrm{NF}-\kappa \beta$ gene expression level in femur bones following ASCs infusion in the OVX rats might be explained by the direct influence of mesenchymal stem cells in bone homeostasis, both by the rate at which they create osteoblasts and by the production of factors affecting the osteoblast/osteocyte balance such as RANKL and OPG (Brooke et al., 2007). In addition, Chai et al., (2012) indicated that MSCs influence hostderived osteoclastogenesis via the production of OPG which increased the OPG/RANKL ratio and thus decreased osteoclast differentiation and activation. Similar reporter assays have clarified the constitutive MSCs secretion of OPG exerts an antierosive effect by decreasing osteoclasts, as it inhibits the binding between RANKL and RANK; this, in turn, prevents osteoclast precursors from differentiating and fusing to form mature osteoclasts. Therefore, the inhibition of the RANK/RANKL pathway inhibits osteoclast formation, differentiation, activation and bone resorption (Narducci et al., 2011 and Oshita et al., 2011). Also, the role of the RANKL in osteoclastogenesis has been established as accumulated evidences have suggested that osteoclast differentiation is principally stimulated by an increase in the ratio of RANKL to OPG in bone (Sato et al., 2007 and Narducci et al., 2011). RANKL mediated NF- $\kappa \beta$ activation via both the classic and alternative pathways leading to increased osteoclast differentiation and survival and decreased osteoblast maturation and function (Novack, 2011). Taken together, these data support the hypothesis that MSCs could affect osteoclastogenesis via the RANK/ RANKL/ OPG signal transduction pathway that regulates osteoclast formation. In addition, given the known immunosuppressive effect of MSCs, it is possible that immunosuppressive soluble mediators contribute to inhibition of osteoclastogenesis (Oshita et al., 2011). Moreover, MSCs are known for their strong anti-inflammatory functions, as they often transplanted into inflammatory environments where they able to survive and modulate host immune responses (Carrero et al., 2012). Consequently this intriguing property might explain the useful therapeutic application of MSCs in osteoporosis as various lines of evidences have indicated that inflammation exerts significant influence on bone turnover in osteoporosis (Nadia et al., 2012).

Concerning the ASCs with IBS treated group, the results evident significant increase in serum OPG level associated with significant decrease in serum RANKL level, in addition to significant down regulation of $\mathrm{NF}-\kappa \beta$ gene expression level in femur bones. These results may be in accordance with the principal that bone formation is an intricate and ordered cascade reaction between relevant stem cells and biomaterials in a continuously renewed internal environment, the procedure of which is regulated by growth factors (Giraud Guille et al., 2005).

In cell based approaches, several reports demonstrated that calcium phosphate bioceramics combined with MSCs ( Kruyt et al., 2007 and Trojani et al., 2006) and/or growth factor (Wang et al., 2010) could induce ectopic bone formation. In the same context, Chai et al., (2012) indicated that stem cell-based strategies for bone regeneration, which use calcium phosphate (CaP)-based biomaterials in combination with developmentally relevant progenitor populations, have significant potential for clinical repair of skeletal defects. As seeding a threshold amount of stem cells into CaP-based biomaterial is a key determinant for CaP-driven ectopic bone formation.

Regarding the mechanism of osteoinduction by biomaterials, Cheng et al., (2013) reported that both $\mathrm{CaP}$ and BCP powders induce osteogenesis because $\mathrm{Ca}$ ions existed in these materials. Meanwhile, in vitro, both trace $\mathrm{CaP}$ and BCP powders could induce osteogenic differentiation of hMSCs, suggesting that chemical composition was the necessary condition of osteogenesis. Also recently, Song et al., (2013) suggested that the BCP granules with HA/ $\beta$-TCP ratio of $5 / 1$, were likely successful in adsorbing endogenous growth factors from the body fluids in vivo, which was manifested by imparting an osteoinductivity to the BCP to achieve ectopic bone formation. Also the ability of such implants to recruit distant MSCs and induce osteogenic differentiation and bone formation is promising for applications in regenerative medicine. Our results for the IBS group indicated the inability of this composite alone to reverse osteoclastogenesis in OVX rats significantly. These results agree with those of Hicok et al., (2004) who observed osteoid formation in $80 \%$ of HA-TCP implants loaded with MSC cells implanted subcutaneously in mice, while in the control HA-TCP implanted without cells, the osteoid formation was not observed. The differences in the experimental protocols could contribute to the shortage effect of IBS in management of osteoclastogenesis. As the injection model used in the present study contrast the direct implantation model used in various reports. However these studies demonstrated a positive effect on using the biomaterials for local treatment of bone diseases, but they require more invasive surgical interventions. Blouin et al., (2006) reported that HMPC /BCP composite implanted in osteoporotic rats induces bone formation. This IBS 
was injected in the holes drilled in the femurs cortex and X-ray examination ensures the corrected implantation of the biomaterials. Soon after implantation, disappearance of the polymer is followed by colonization of the implant site by cells and neovascularization leading to the deposit of woven bone around BCP granules. Also extensive studies indicated that the first generation IBS composites, which consists of a water soluble $3 \%$ cellulosic polymer (like HPMC), needed the improvement of its properties by grafting silane to HPMC. This Si-HPMC hydrogel have been set up to make it easy to manipulate in vitro and to inject in vivo (Trojani et al., 2006). In conclusion, the present study highlighted the potential role of adipose derived mesenchmal stem cells (ASCs) in reducing osteoclastogenesis in ovariectomized rats. In addition, the combination of ASCs with osteoinductive material, injectable calcium phosphate composite (IBS), represents a novel approach with significant importance in management of osteoporosis.

\section{REFERENCES}

Alhadlaq A, Mao JJ. Mesenchymal stem cells: isolation and therapeutics. Stem Cells Dev., 2004; 13:436-448.

Anandarajah AP. Role of RANKL in bone diseases. Trends in Endocrinology and Metabolism, 2009; 20 (2): 88-94.

Armitage P, Berry G. 1987. Comparison of several groups. In: statistical method in medical research 2th Ed. Blockwell Significant Publication. Oxford: 186-213.

Blouin S, Moreau MF, Weiss P, Daculsi G, Basle' MF, Chappard D. Evaluation of an injectable bone substitute ( $\beta$ $\mathrm{TCP} /$ hydroxyapatite/hydroxy-propyl-methyl-cellulose) in severely osteopenic and aged rats. Inc. J Biomed Mater Res., 2006; 78(A): 570580.

Boyce BF, Yao Z, Xing L. Functions of NF- $\kappa \beta$ in Bone. Ann N Y Acad Sci., 2010; 1192: 367-375.

Bradford PG, Gerace KV, Roland RL, Chrzan BG. Estrogen regulation of apoptosis in osteoblasts. Physiology \& Behavior, 2010; 99: 181-185.

Brooke G, Cook M, Blair C, Han R, Heazlewood C, Jones B, et al., Therapeutic applications of mesenchymal stromal cells. Seminars in Cell \& Developmental Biology, 2007; 18:846-858.

Cardemil C, Omara OM, Norlindh B, Wexell CL, Thomsen P. The effects of a systemic single dose of zoledronic acid on postimplantation bone remodelling and inflammation in an ovariectomised rat model. Biomaterials, 2013; 34:1546-1561.

Carrero R. Cerrada I, Lledó E, Dopazo J, García-García F, Rubio M, et al., IL1 $\beta$ Induces Mesenchymal Stem Cells Migration and

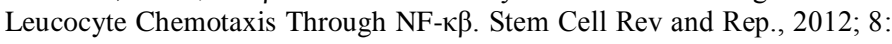
905-916.

Casteilla L, Planat-Benard V, Laharrague P, Cousin B. Adiposederived stromal cells: Their identity and uses in clinical trials, an update. World J Stem Cells, 2011; 3(4): 25-33.

Chai YC, Roberts SJ, Desmet E, Kerckhofs G, van Gastel N, Geris L, et al., Mechanisms of ectopic bone formation by human osteoprogenitor cells on $\mathrm{CaP}$ biomaterial carriers. Biomaterials, 2012; 33:3127-3142.

Chang J, Wang Z, Tang et al., Inhibition of osteoblastic bone formation by nuclear factor- $\kappa \beta$. Nat Med., 2009; 15:682-689.

Cheng L, Shi Y, Ye F, Bu H. Osteoinduction of calcium phosphate biomaterials in small animals. Materials Science and Engineering C., 2013; 33: 1254-1260.

D'Amelio, P. et al., Estrogen deficiency increases osteolcastogenesis up regulating $\mathrm{T}$ cells activity: a key mechanism in osteoporosis. Bone, 2008; 43, 92-100.
Dalle Carbonare L, Valenti MT, Zanatta M, Donatelli L, Lo Cascio V. Circulating Mesenchymal Stem Cells With Abnormal Osteogenic Differentiation in Patients With Osteoporosis. Arthritis and Rheumatism, 2009; 60 (11): 3356-3365.

Di'az-Curiel M, Gala JL: Is the ovariectomized rat an appropriate model to study osteoporosis in postmenopausal human subjects. Revista Española de Enfermedades Metabólicas O 'seas, 1994; 3:83-84.

Eastell R. Identification and management of osteoporosis in older adults. Medicine, 2013; 41(1): 47-52.

Fong EL, Chan CK, Goodman SB. Stem cell homing in musculoskeletal injury. Biomaterials, 2011; 32: 395-409.

Giraud Guille MM, Mosse G, Helary C, Eglin D. Bone matrix like assemblies of collagen: from liquid crystals to gels and biomimetic materials. Micron, 2005; 36:602-8.

Hicok KC, Du Laney TV, Zhou YS, Halvorsen YD, Hitt DC, Cooper LF. et al., Human adipose-derived adult stem cells produce osteoid in vivo. Tissue Eng., 2004; 10:371-38.

Kang SK, Shin IS, Ko MS, Jo JY, Ra JC. Journey of Mesenchymal Stem Cells for Homing: Strategies to Enhance Efficacy and Safety of Stem Cell Therapy. Stem Cells International, 2012; 2012:1-11.

Kobayashi Y, Udagawa N, Takahashi N. Action of RANKL and OPG for osteoclastogenesis. Crit Rev Eukaryot Gene Expr., 2009; 19:6172 .

Krum SA, Chang J, Miranda-Carboni G, Wang CY. Novel functions for NF- $\kappa \beta$ : inhibition of bone formation. Nat Rev Rheumatol., 2010; 6(10): 607-611

Kruyt MC, Dhert WJ, Oner FC, van BC, Verbout AJ, Bruijn JD. Analysis of ectopic and orthotopic bone formation in cell-based tissueengineered constructs in goats. Biomaterials, 2007; 28:1798-805.

Lau HY, Bhatia M. Effect of CP-96,345 on the expression of adhesion molecules in acute pancreatitis in mice. Am J Physiol Gastrointest Liver Physiol., 2007; 292: 1283-1292.

Li DF, Yang C, Li Z, Yuan LL, Dai JX, Yuan L. Immunophenotypic comparison of adipose-derived mesenchymal stem cells from the greater omentums and subcutaneous adipose tissues of rats. Nan Fang Yi Ke Da Xue Xue Bao., 2010; 30 (10): 2256-8, 2262.

Livak KJ, Schmittgen TD. Analysis of Relative Gene Expression Data Using Real-Time Quantitative PCR and the 22DDCT. Methods, 2001; 25: 402-408.

Mattila P. Dietary xylitol in the prevention of experimental osteoporosis. Acta universitalis ouluensis medical, 1999; 510:1-76.

Miyazaki T, Matsunaga T, Miyazaki S, Hokari S, Komoda T. Changes in receptor activator of nuclear factor $\kappa \beta$ and its ligand, osteoprotegerin, bone type alkaline phosphatase and tartrate resistant acid phosphatase in ovariectomized rats. J. Cell.Biochem., 2004; 93: 503-512.

Muñoz-Fernández R, Blanco FJ, Frecha C, Martín F, Kimatrai M, Abadía-Molina AC, et al., Follicular dendritic cells are related to bone marrow stromal cell progenitors and to myofibroblasts. J Immunol., 2006; 177: 280-289.

Nadia ME, Nazrun AS, Norazlina M, Isa NM, Norliza M, and Ima Nirwana S. The Anti-Inflammatory, Phytoestrogenic, and Antioxidative Role of Labisia pumila in Prevention of Postmenopausal Osteoporosis. Advances in Pharmacological Sciences, 2012; 2012:1-7.

Nakamura T, Sakata R, Ueno T, Sata M, Ueno H. Inhibition of transforming growth factor beta prevents progression of liver fibrosis and enhances hepatocyte regeneration in dimethylnitrosamine-treated rats. Hepatol., 2000; 32: 247-255.

Narducci P, Bareggi R, Vanessa N. Receptor Activator for Nuclear Factor kappa- $\beta$ Ligand (RANKL) as an osteoimmune key regulator in bone physiology and pathology. Acta histochemica, 2011; 113:73-81.

Novack DV. Role of NF- $\kappa \beta$ in the skeleton. Cell Research, $2011 ; 21: 169-182$

Ominsky MS, Li X, Asuncion FJ, et al., RANKL inhibition with osteoprotegerin increases bone strength by improving cortical and trabecular bone architecture in ovariectomized rats. Journal of Bone and Mineral Research, 2008; 23:672-682. 
Orlić I, Borovecki F, Simić P, Vukicević S. Gene expression profiling in bone tissue of osteoporotic mice. Arh Hig Rada Toksikol., 2007; 58(1):3-11.

Oshita K, Yamaoka K, Udagawa N, Fukuyo S, Sonomoto K, Maeshima K, et al., Human Mesenchymal Stem Cells inhibit osteoclastogenesis through osteoprotegerin production. Arthritis and Rheumatism, 2011; 63: 1658-1667.

Peister A, Mellad JA, Larson BL, Hall BM, Gibson LF, Prockop DJ. Adult stem cells from bone marrow (MSCs) isolated from different strains of inbred mice vary in surface epitopes, rates of proliferation and differentiation potential. Blood, 2004; 103:1662-1668.

Phinney DG, Kopen G, Isaacson RL, Prockop DJ. Plastic adherent stromal cells from the bone marrow of commonly used strains of inbred mice: variations in yield, growth and differentiation. J Cell Biochem., 1999; 72: 570-585.

Pino AM, Clifford J, Rosen CJ, Rodríguez JP. In Osteoporosis, differentiation of mesenchymal stem cells (MSCs) improves bone marrow adipogenesis. Biol Res., 2012; 45: 279-287.

Pittenger MF, Mackay AM, Beck SC, Jaiswal RK, Douglas R, Mosca JD, et al., Multilineage potential of adult mesenchymal stem cells. Science, 1999; 284: 143- 147.

Porichi O, Nikolaidou M, Apostolaki A, Tserkezoglou A, Arnogiannaki N, Kassanos D. BCL-2, BAX and P53 Expression Profiles in Endometrial Carcinoma as Studied by Real-time PCR and Immunohistochemistry. Anticancer Research, 2009; 29: 3977-3982.

Qin H, Zhao L, Sun J, Ren L, Guo W, Liu H, et al., The differentiation of mesenchymal stem cells into inner ear hair cell-like cells in vitro. Acta Oto-Laryngologica, 2011; 131: 1136-1141.

Ren ZW, Zhao Z, Wang Y, Chen JF, Zhan SF, Liu Y, et al., Study on differentiation of rat adipose tissue-derived stromal cells into Schwann-like cells. Zhongguo Ying Yong Sheng Li Xue Za Zhi., 2011; 27(4):385-8.

Rice CM, Scolding NJ. Autologous bone marrow stem cells properties and advantages. Journal of the Neurological Sciences, 2008; 265: 59-62.

Rochefort GY, Vaudin P, Bonnet N, Pages JC, Domenech J, Charbord $\mathrm{P}$, et al., Influence of hypoxia on the domiciliation of mesenchymal stem cells after infusion into rats: possibilities of targeting pulmonary artery remodeling via cells therapies. Respir Res., 2005; 6:125.

Rombouts WJ, Ploemacher RE. Primary murine MSC show highly efficient homing to the bone marrow but lose homing ability following culture. Leukemia, 2003; 17:160-170.

Sachs PC, Francis MP, Zhao M, Brumelle J, Rao RR, Elmore LW, Holt SE. Defining essential stem cell characteristics in adiposederived stromal cells extracted from distinct anatomical sites. Cell Tissue Res., 2012; 349(2):505-15.

Sato T, Watanabe K, Masuhara M, Hada N, Hakeda Y. Production of IL-7 is increased in ovariectomized mice, but not RANKL mRNA expression by osteoblasts/stromal cells in bone, and IL-7 enhances generation of osteoclast precursors in vitro. J Bone Miner Metab., 2007; 25:19-27.

Schäfer S, Calas A, Vergouts M, Hermans E. Immunomodulatory influence of bone marrow-derived mesenchymal stem cells on neuroinflammation in astrocyte cultures. J Neuroimmunol., 2012; 249: 40-48.

Schermer S, 1967. The Blood Morphology of Laboratory Animals, $3^{\text {rd }}$ ed., F.A. Davi., Phladelphia, pp: 42.

Sherman KP. Metabolic bone disease. Orthopaedics and Trauma, 2012; 26(3): 220-225.
Silva I, Branco JC. rank / rankl / opg: literature review. Acta Reumatol Port, 2011; 36:209-218.

Song G, Habibovic P, Bao C, Hu J, van Blitterswijk CA, Yuan $\mathrm{H}$, et al.The homing of bone marrow MSCs to non-osseous sites for ectopic bone formation induced by osteoinductive calcium phosphate. Biomaterials, 2013; 34: 2167-2176.

Tomiyama K, Murase N, Stolz DB, Toyokawa H, O’Donnell DR, Smith DM, et al., Characterization of Transplanted GFP+ Bone Marrow Cells into Adipose Tissue. Stem Cells, 2008; 26:330-338.

Trojani C, Boukhechba F, Scimeca JC, Vandenbos F, Michiels $\mathrm{JF}$, Daculsi G, et al., Ectopic bone formation using an injectable biphasic calcium phosphate/Si-HPMC hydrogel composite loaded with undifferentiated bone marrowstromal cells. Biomaterials, 2006; 27:325664.

Trounson A, Thakar RG, Lomax G, Gibbons D. Clinical trials for stem cell therapies. BMC Medicine, 2011; 9:52.

Trouvin A, Goëb V. Receptor activator of nuclear factor- $\kappa \beta$ ligand and osteoprotegerin: maintaining the balance to prevent bone loss.Clinical Interventions in Aging, 2010; 5: 345-354.

Wang HS, Hung SC, Peng ST, Huang CC, Wei HM, Guo YJ, et al., Mesenchymal stem cells in the Wharton's jelly of the human umbilical cord. Stem Cells, 2004; 22:1330-1337.

Wang L, Huang Y, Pan K, Jiang X, Liu C. Osteogenic responses to different concentrations/ratios of BMP-2 and $\beta F G F$ in bone formation. Ann Biomed Eng., 2010; 38:77-87.

Wu GD, Tuan TL, Bowdish ME, Jin YS, Starnes VA, Cramer DV. Evidence for recipient derived fibroblast recruitment and activation during the development of chronic cardiac allograft rejection. Transplantation, 2003; 76:609-14.

Yamachika E, Iida S. Bone regeneration from mesenchymal stem cells (MSCs) and compact bone-derived MSCs as an animal model Japanese Dental Science Review, 2013; 49:35-44.

Yamazaki M, Fukushima H, Shin M, et al., Tumor necrosis factor $\alpha$ represses bone morphogenetic protein (BMP) signaling by interfering with the DNA binding of Smads through the activation of NF$\kappa \beta$. J Biol Chem., 2009; 284:35987-35995.

Ying C, Hu W, Cheng B, Zheng X, Li S. Neural differentiation of rat adipose-derived stem cells in vitro. Cell Mol Neurobiol., 2012; 32(8):1255-63.

Zhang Y, Dong XL, Leung PC, Wong MS. Differential mRNA expression profiles in proximal tibia of aged rats in response to ovariectomy and low-Ca diet. Bone, 2009; 44:46-52.

Zhao DC, Lei JX, Chen R, Yu WH, Zhang XM, Li SN. Bone marrow-derived mesenchymal stem cells protect against experimental liver fibrosis in rats. World J Gastroentrol., 2005; 14: 3431-3440.

Zhu X, Luo J, Chen X, Wang J, Wang G, Li $\mathrm{H}$, et al., Expression characteristic and significance of interleukin-6, nuclear factor kappa beta, and bone formation markers in rat models of osteoporosis. Translational Research, 2008; 152:18-23.

\section{How to cite this article:}

Hanaa H. Ahmed, Wafaa Gh. Shousha, El-Sayed M. El-Sayed Mahdy, Laila A. Rashed, Sara M. Abdo., Influence of adipose tissue derived mesenchymal stem cells in combination with injectable bone substitute on osteoclastogenesis in osteoporotic rats. J App Pharm Sci. 2013; 3 (08): 046-056. 